\title{
Bushmaster (Lachesis muta) predatory behavior at Dallas Zoo and San Diego Zoo
}

\author{
DAVID CHISZAR \\ University of Colorado, Boulder, Colorado \\ JAMES B. MURPHY \\ Dallas Zoo, Dallas, Texas \\ CHARLES W. RADCLIFFE \\ San Diego Zoo, San Diego, California \\ and \\ HOBART M. SMITH \\ University of Colorado, Boulder, Colorado
}

\begin{abstract}
Bushmasters (Lachesis muta) that were observed during feeding episodes occasionally released rodents after the predatory strike. For one such episode, we report the presence of a sustained, high rate of tongue-flicking that lasted $136 \mathrm{~min}$. In this paper, we also present photographs showing skin folds that cover the snake's pits and eyes when a rodent prey was being held following the predatory strike. We suggest that $L$. muta may occasionally exhibit strike-induced chemosensory searching and trail-following when large (but ingestible) prey are encountered.
\end{abstract}

Adult bushmasters (Lachesis muta), which may exceed $3 \mathrm{~m}$ in length, typically hold rodent prey following the envenomating strike (J.B.M. and C.W.R., personal observations, 1986-present, while feeding bushmasters meals ranging from $1.5 \%-3.0 \%$ of snake body weight). These snakes have facial characteristics similar to those described for Porthidium nummifer by Chiszar and Radcliffe (in press); the pits and eyes are partly or completely covered by skin folds during the period that a prey item is held (see Figure 1). Hence, we suspect that facial receptors are protected from injury that could be caused by struggling rodents. Nevertheless, yearling bushmasters at Dallas Zoo sometimes released large (but ingestible) rodents following the strike. A systematic analysis of this behavior, varying prey size and recording whether snakes hold or release the prey, is currently in progress (D. Boyer, personal communication, March 15, 1989).

Upon observing several yearlings after they had struck and released large rodents, we noticed a sustained, high rate of tongue-flicking coupled with searching movements that, collectively, resembled the strike-induced chemosensory searching (SICS) typically seen in various species of rattlesnakes that routinely release rodent prey (Chiszar, Radcliffe, Scudder, \& Duvall, 1983). We decided, therefore, to make systematic records of bushmaster behavior

The authors thank the herpetological staffs at Dallas Zoo and San Diego Zoo for their support and encouragement. Reprint requests may be sent to D. Chiszar, Department of Psychology, Campus Box 345, University of Colorado, Boulder, CO 80309. upon releasing prey in order to quantify SICS. This paper reports our initial observations.

\section{METHOD}

Three yearling bushmasters, hatched at Dallas Zoo (August 15-18, $1987)$, were observed. Two were exposed to rats $(60 \mathrm{~g})$ held just outside of striking range for $3 \mathrm{sec}$ (i.e., no-strike, or control, condition). These prey were then removed, and all tongue flicks emitted by the snakes were recorded during the next $10 \mathrm{~min}$. The third snake was permitted to strike the rat after the 3-sec exposure. This snake released the prey within $5 \mathrm{sec}$. We then removed the prey from the snake's cage. Tongue flicks were recorded continuously until the snake reached a criterion of 10 successive minutes with zero tongue flicks. All rats were euthanized just prior to use in this study; hence, live rodents were not being exposed to snakes. All rat carcasses were eventually fed to snakes.

To obtain a predisturbance baseline, we observed each snake for $5 \mathrm{~min}$ prior to presenting prey.

The snakes were individually housed in wooden cages $(54 \times 25 \times$ $28.5 \mathrm{~cm}$ ) with glass fronts and screen tops. Floors were covered with paper, and ad-lib water was available. Temperature $\left(25^{\circ} \mathrm{C}\right)$, humidity (40\%), and photoperiod (0700-2000 h) were electrically controlled, except that natural dawn and dusk were provided by overhead windows. Conditions were comparable at San Diego Zoo, where adult bushmasters were photographed during typical feeding episodes.

\section{RESULTS AND DISCUSSION}

Photographs taken during a typical feeding session at San Diego Zoo revealed the presence in adult bushmasters of skin folds that cover the pits while these snakes hold prey (cf. Chiszar \& Radcliffe, in press). We suspect holding to be a regular feature of predatory behavior in the snakes, and we hypothesize that the skin folds protect the pits and eyes from rodent retaliatory behavior. 

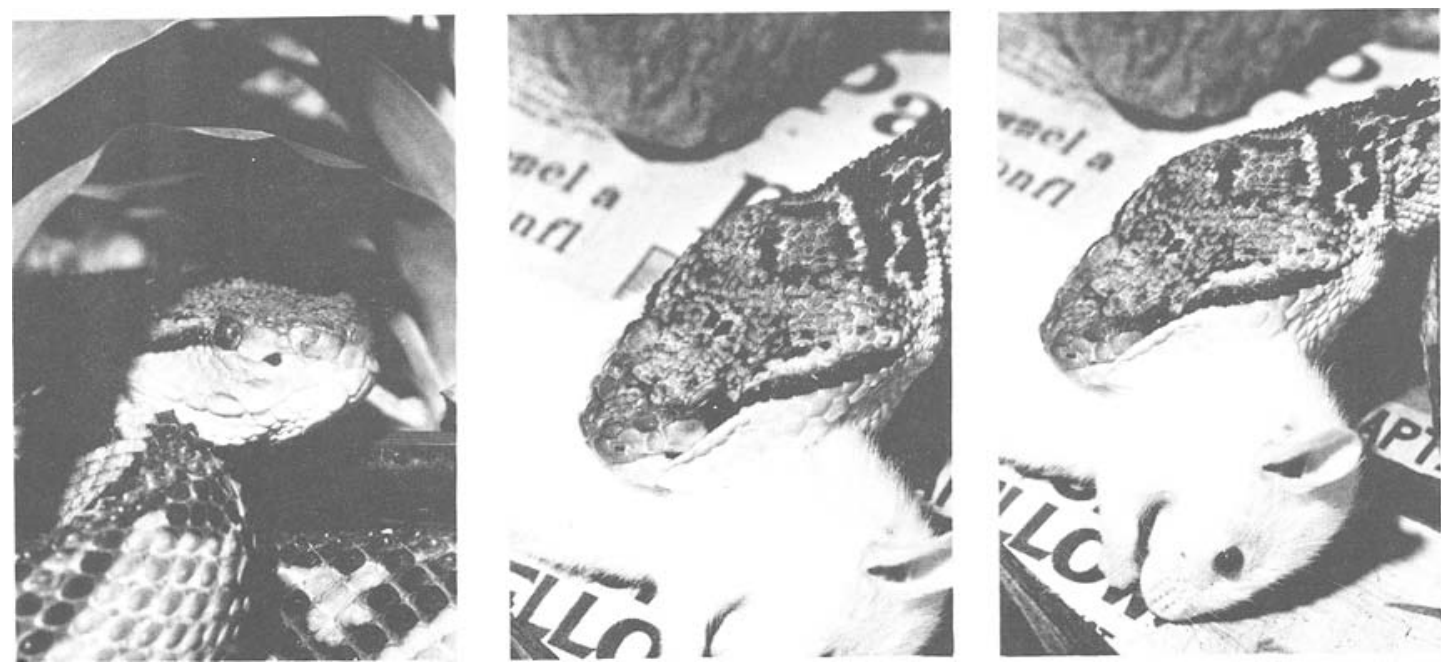

Figure 1. The left panel shows a bushmaster in ambushing posture, with its pits clearly visible. The center panel shows the same snake just after striking a rat, and the pits are partly covered by skin folds. The right panel shows the snake several seconds later, with its pits completely covered and its eyes partly covered. Photographs taken by Ron Garrison, Zoological Society of San Diego. Copyright 1988 by Zoological Society of San Diego. Reprinted by permission.

Among the yearlings at Dallas Zoo, the rate of tongueflicking (RTF) during the baseline period was zero, indicating that the snakes were quiescent prior to presentation of prey (Figure 2). Following no-strike presentations, there was a small rise in RTF followed by a rapid return to baseline, revealing that the bushmasters were not stimulated to search in this condition. The predatory strike, however, was followed by a very high RTF that was sustained for the 30-min period shown in Figure 2. Furthermore, the snake did not begin the criterion run of 10 successive minutes with zero RTF until Poststrike Minute 136 (2.26 h). A comparison of the RTF during Minutes 1-10 following no-strike presentations with the RTF during Minutes 1-10 following the strike presentation revealed a robust difference $[t(1)=132.14, p<.05]$.
Although only one bushmaster was observed in the strike condition, the behavior of this animal resembled that seen in numerous similar experiments with rattlesnakes (Chiszar, Radcliffe, \& Feiler, 1986). The snake methodically searched throughout its cage, as if it were seeking a prey carcass or a trail that would lead to one. Accordingly, we strongly suspect that SICS will turn out to be a reliable feature of predatory episodes involving large prey that are struck and released by young bushmasters. At the very least, the present data can be taken as ample justification for conducting experiments along these lines.

Two questions stand out as being of primary importance. First, is the tendency to release large prey a characteristic of juvenile bushmasters, or will adults also ex-

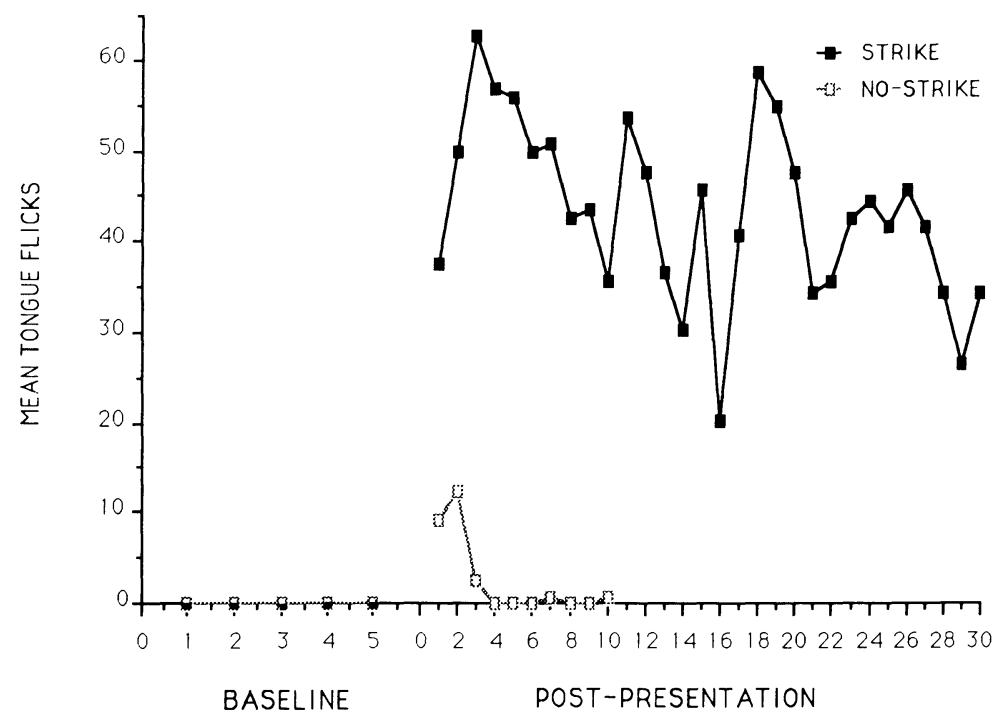

Figure 2. Mean rate of tongue-flicking during a baseline period of no disturbance and after strike and no-strike presentations of rodent prey (see text). 
hibit this behavior when they are offered large (but ingestible) prey? Second, do bushmasters of any age release prey under natural conditions? Assessment of the ontogenetic and/or ecological significance of the present findings depends upon the answers to these questions (cf. Greene, 1986; Greene \& Santana, 1983).

\section{REFERENCES}

Chiszar, D., \& Radcliffe, C. W. (in press). The predatory strike of the jumping viper (Porthidium nummifer). Copeia.

Chiszar, D., Radcliffe, C. W., \& Feiler, F. (1986). Trailing behavior in banded rock rattlesnakes (Crotalus lepidus klauberi) and prairie rattlesnakes (C. viridis viridis). Journal of Comparative Psychology, 100, 368-371.

Chiszar, D., Radcliffe, C. W., Scudder, K. M., \& Duvall, D. (1983). Strike-induced chemosensory searching by rattlesnakes: The role of envenomation-related chemical cues in the post-strike environment. In D. Muller-Schwarze \& R. Silverstein (Eds.), Chemical signals in vertebrates III (pp.1-24). New York: Plenum.

GREENE, H. W. (1986). Natural history and evolutionary biology. In M. E. Feder \& G. V. Lauder (Eds.), Predator-prey relationships (pp. 99-108). Chicago: University of Chicago Press.

Greene, H. W., \& Santana, M. A. (1983). Field studies of hunting behavior by bushmasters. American Zoologist, 23, 897.

(Manuscript received March 29, 1989.) 